\title{
Increasing Incidence of Malignancy Among Male Breast Lesions in The Urban Population of India
}

\author{
Sujata Mallick ${ }^{1}$ and Mahasweta Mallik ${ }^{2 *}$ \\ 'Pathology Department, KPC medical college, Jadavpur, Kolkata, West Bengal., India \\ ${ }^{2}$ Pathology Department, Govt. Medical College, Ambikapur, Chasttisgarh, India
}

\begin{abstract}
Background: Among the male breast lesion gynaecomastia is the most common lesion present. Breast malignancy accounts for less than $1 \%$ of all male malignancy. Aim of this study was to see the increasing incidence of breast carcinoma among males in India

Methods: A retrospective studywas undertaken in KPC Medical College, catering to an urban population, over a period of three and a half years. 32 male breast lesionswhich presented in the surgery department were analysed.

Result: $75 \%$ of the cases were gynaecomastia which is the most common male breast lesion,other benign breast lesions like epidermal cyst, breast abscess and fibroadenomacomprised $9.3 \%$ of the total lesions present.Breast carcinoma, In situ lesion and sarcoma of the breast accounted for $15.5 \%$ of the cases.

Conclusion: Worldwide studies have shown male breast carcinoma to be less than $1 \%$. Our study showed a prevalence of $15.5 \%$ breast malignancy, showing a phenomenal increase in breast carcinoma among male patient.
\end{abstract}

Keywords: Breast Carcinoma, Gynaecomastia, Hormone, Fibroadenoma

\section{Introduction}

The prevalence of male breast lesions in the population is not studied as well as female breast pathologies. However, the urban population is becoming more conscious and male patients with swelling or lump in the breast are presenting themselves in the OPD. In male breast, gynaecomastia is the most common lesion seen. It is mainly due to the hormonal changes seen during puberty. Non neoplastic lesions like sebaceous cyst and breast abscess accounts for the second most common breast pathology in males. Among neoplastic lesions, male breast carcinoma was believed to be rare, accounting for $1 \%$ of all malignancies in male ${ }^{[1]}$. Fibroadenoma in male breast is very rare due to the absence of lobules in the male breast ${ }^{[2]}$. Mostly fibroadenoma is due to the patient's hormonal treatment ${ }^{[3]}$. The aim of this study was to highlight the increasing incidence of breast carcinoma amongst all the lesions of the male breast in India.

\section{Materials and Methods}

This is a retrospective study of males presenting with breast lump who attended both the outpatient as well as the inpatient department of surgery in KPC medical college, situated in the heart of the metropolitan city of Kolkata and catering to an urban population. The study was from May 2014 to December2017, a period of 3 and half years. As this was a retrospective study, no patient consent was needed. No ethical issues were also present in this study. There were a total of 37 males who came with the complaint of swelling of breast. Fine needle aspiration cytology was done from the swelling. This was followed by trucut biopsy, lumpectomy and histopathological corelation. Hematoxylin and Eosin stained slides were reviewed by more than 2 pathologists in doubtful cases. Immunohistochemistry was applied where required for diagnosis. 5 male patients presented with breast swelling and FNAC showed benign breast lesions but they did not turn up for histopathological examination and were excluded from our study. All the carcinoma and sarcoma cases were referred to higher oncology centres for further treatment and follow up.

\section{Result}

Patients were between the ages of 17 years to 72 years with a mean of 28.2 years. The results were classified into benign and malignant.

Benign breast lesions- 24 patients were of gynaecomastia with ductal epithelial hyperplasia with flat or papillary pattern, increased periductal stromal cellularity and oedema. Some cases showed fibrous phase with less epithelial proliferation and more collagenous stroma. Patient with breast abscess was a 32year old male showing breast tissue with a cavity filled with dense neutrophilic infiltrate.Patient with benign epidermal cyst was a 50 year 
old man showing cornified epithelium and lamellated keratin in histopathological microscopic section. Patient of fibroadenoma was 24 years old showing typical branching sheets of ductal cells, with fibromyxoid stroma and bare oval nuclei in FNAC. Histopathological finding showed intracanalicular type of fibroadenoma with slit like glands and myxoid stroma.

Malignant lesion- All the patients whose report showed suspicious of malignancy in fine needle aspiration cytology were confirmed by trucut biopsy later by radical mastectomy. 3 patients were positive for Infiltrating Ductal Carcinoma ( No Specific Type), aged 54 years, 62 years and 64 years respectively. The reporting was done based on CAP protocol. Sheets of pleomorphic tumour cells with no myoepithelial cells were seen in $\mathrm{H} / \mathrm{E}$ stained slides. Tubular formation was preserved in some parts. Pathological grading (Nottingham Grading system) was grade 2 in the first two cases and grade 3 in the third case. There was no lymph node isolated in the first case. In the second case, 4 lymph nodes were isolated which were reactive. In the third case, out of 8 lymph node identified, 3 were positive for malignancy.

One patient having ductal carcinoma in situ was a 45 years old male, showing cribiform pattern without necrosis in histopathological sections. Nuclear: cytoplasmic ratio was increased with few mitotic figures.

One patient was of dermatofibrosarcoma protuberans of breast, and was aged 72 years, showing spindled fibroblastic cells with interdigitating fasciculated and storiform growth pattern and thin walled blood vessels. High mitotic activity around 9-10/hpf was seen. Immunohistochemistry showed vimentin, CD 34 and CD 99 positivity and was negative for CK 7, S-100, Desmin, SMA, HMB-45 and EMA.

Table 1: Histopathological evaluation of total 32 cases of male breast lump with their ages.

\begin{tabular}{|c|c|c|c|c|c|c|c|}
\hline & \multicolumn{4}{|c|}{ Benign Breast Lesions } & \multicolumn{3}{c|}{ Malignant lesion } \\
\hline Lesion & Gynaecomastia & $\begin{array}{c}\text { Breast } \\
\text { Abscess }\end{array}$ & $\begin{array}{c}\text { Benign } \\
\text { EpidermalCyst }\end{array}$ & Fibroadenoma & $\begin{array}{c}\text { Ductal } \\
\text { carcinoma } \\
\text { in situ }\end{array}$ & $\begin{array}{c}\text { Invasive } \\
\text { Ductal } \\
\text { Carcinoma } \\
\text { Dermatofibro- } \\
\text { sarcoma } \\
\text { protuberance }\end{array}$ \\
\hline No. of Cases & $24(75 \%)$ & $1(3.1 \%)$ & $1(3.1 \%)$ & $1(3.1 \%)$ & $1(3.1 \%)$ & $3(9.3 \%)$ & $1(3.1 \%)$ \\
\hline Age & $17-35$ years & 32 years & $50 y e a r s$ & $24 y e a r s$ & $45 y e r s$ & $\begin{array}{c}54,64,62 \\
\text { years }\end{array}$ \\
\hline
\end{tabular}

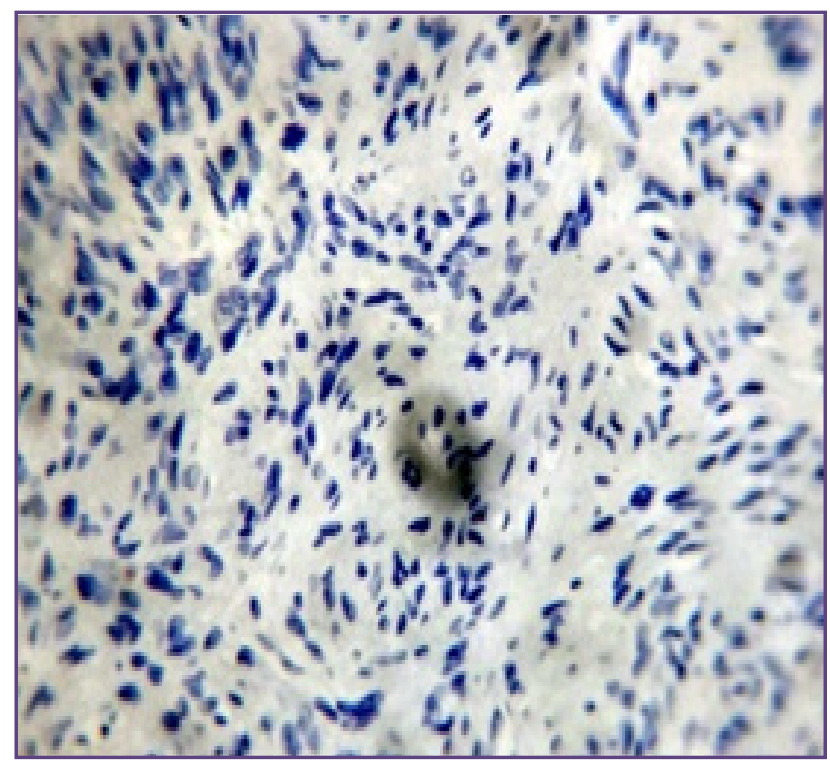

Fig. 1: Dermatofibrosarcoma protuberance. 400X magnification, $\mathrm{P} 63$ positive.

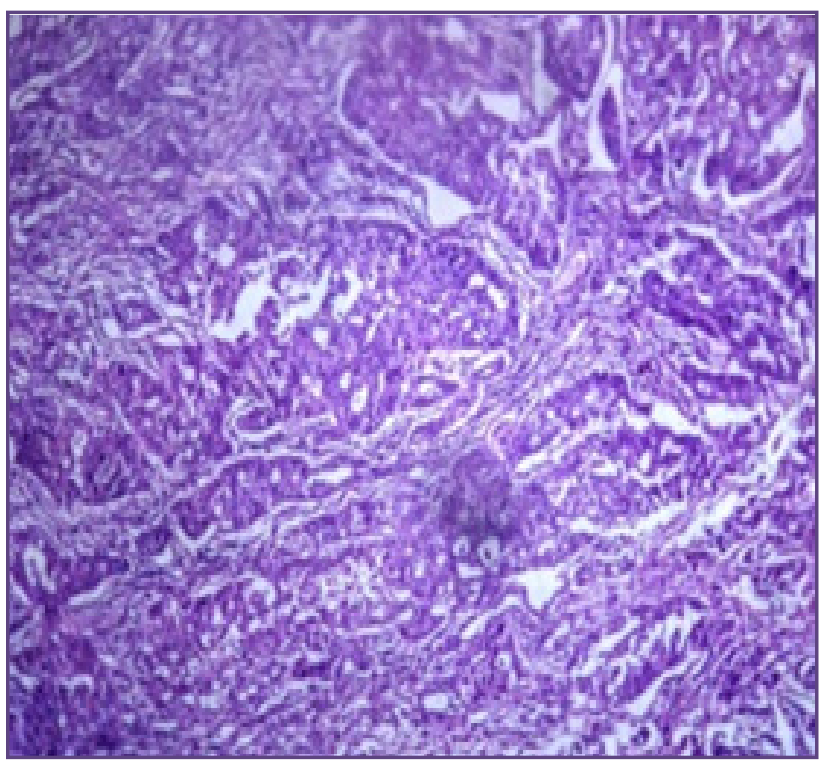

Fig. 2 :Invasive ductal carcinoma(100X,H\&E stain). 


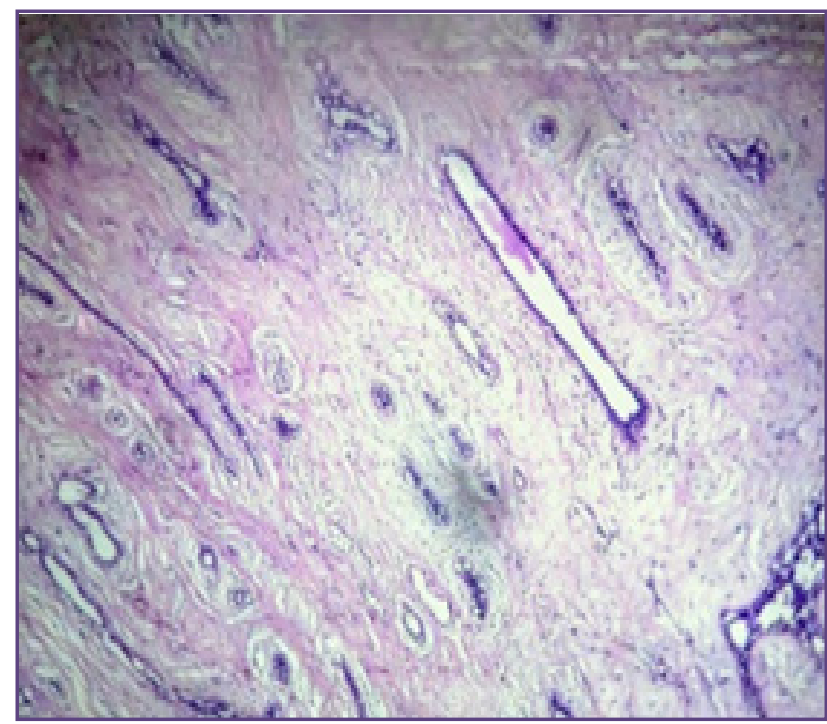

Fig. 3: Fibroadenoma (100X,H\&E stain).

\section{Discussion}

In our study gynaecomastia was $75 \%$, benign breast disease like fibroadenoma, breast abscess, benign epidermal cyst was $9.3 \%$, breast malignancy was $15.4 \%$. Study by Goyal et al showed gyaecomastia $45.5 \%$, benign breast lesion $24 \%$, ductal cancer $18.2 \%$ and lipoma $12.1 \%{ }^{[4]}$.

Fibroadenoma has been documented very rarely in medical literature as case reports and rarely as series of four patients. Hormonal imbalance is the main cause of proliferative changes in the male breast leading to lobular differentiation and fibroepithelial lesions. In most fibroadenoma, gynaecomastia is a consistent feature but in rare cases lobular differentiation is seen without gynaecomastia ${ }^{[5,6,7]}$. Our patient had fibroadenoma with gynaecomastia. In some literature fibroadenoma has been reported in transsexual ${ }^{[8,5]}$.

Epidermoid cyst are more common in scalp, face and back. The source of epidermis is the infundibulum of hair follicle ${ }^{[9]}$. Epidermoid cysts are usually asymptomatic and slow growing till it is infected secondarily. Giant epidermoid cysts are more prone to develop cancer ${ }^{[10,11,12]}$.

Breast abscess in our study was 3.4\%. It was subaereolar in location. FNAC confirmed abscess. Incision and drainage was done. No predisposing cause was present.

Breast cancer has been seen to be $1 \%$ of all malignancy in men ${ }^{[1]}$. Our study showed carcinoma to be $12.5 \%$. Some other studies have also shown increasing incidence of male breast cancer in the last two decades. Study by Goyal et al in 2015 also showed incidence of ductal carcinoma in male breast to be $18.2 \%^{[4]}$. Risk factors for both male and female breast cancer are genetic, exposure to radiation, endocrine disorder, advance age, history of benign breast disease. In males, old age, high socio-economic status, exposure to female hormone and patients with decreased testicular function are more prone to develop breast cancer. Sometimes obesity is also considered a risk factor because fat cells may convert androgens to estrogens ${ }^{[13,14]}$. Breast cancer can be associated with gynaecomastia ${ }^{[15]}$. Chronic alcoholics have increased incidence as alcohol cause liver cirrhosis which leads to hormonal imbalance causing cancer ${ }^{[16]}$. Male breast cancer occurs 5-10 years later than female breast cancer ${ }^{[17]}$. Bilateral involvement is less than $2 \%{ }^{[18]}$. As male breast is smaller in size, so carcinoma is located near the nipple. So spread to the nipple is common with nipple ulceration and discharge ${ }^{[19]}$.

Breast sarcoma are rare tumour with incidence of $<1 \%$ of all breast malignancy ${ }^{[20]}$. Very few cases have been reported in the literature ${ }^{[21,22,23]}$. Berg et al first described stromal sarcomas ${ }^{[24]}$. Stromal sarcomas rarely involves lymphnodes. Cailery et al found negative regional lymph node in 25 patients studied. Our case also had negative lymph node. Age incidence of sarcoma is higher than that of ductal carcinoma ${ }^{[25]}$.

\section{Conclusion}

Due to varied spectrum of male breast lesion and increasing incidence of carcinoma as well as sarcoma in the urban male population, all male breast swelling should be thoroughly investigated for earlier diagnosis of cancer so as to prevent morbidity and mortality due to it.

\section{Acknowledgements}

Technical staff of KPC medical college.

\section{Reference}

1. Fentiman IS, Fourquet A, Hortobagyi GN. Male breast cancer. Lancet 2006;367:595-604

2. Gupta P, Foshee S, Garcia-Morales F, Gray T. Fibroadenoma in male breast:Case report and literature review. Breast Dis 2011;33:45-8

3. Shin SJ, Rosen PP. Bilateral presentation of fibroadenoma with digital fibroma-like inclusions in the male breast. Arch Pathol Lab Med 2007;131:1126-9.

4. Goyal S, Goyal S, Trikha A. Fibroadenoma in male breast. Case report and review. Clin Cancer Investig J 2015;4:220-2.

5. Lemmo G, Garcea N, Corsello S,T, Palladino T, Ardito G et al. Mammary fibroadenoma in a male-to female transsexual patient hormone treatment. Eur J Surg Suppl 2003;588:69-71.

6. Davis SE, Wallace AM. A 19 year old with complete androgen insensitivity syndrome and juvenile fibroadenoma of the breast. Breast J 2001;7:430-3.

7. Nuttall FQ. Gynaecomastia as a physical finding in normal men. J Clin Endocrinol Metab 1979;48:338-40. 
8. Rosen PP.Benign proliferative lesions of the male breast. In:Rosen PP, editor. Rosen's Breast Pathology. 2nd ed. Philadelphia. Pa:Lippincott Williams and Wilkins;2001. pp.703-712.

9. Fujiwara M, Nakamira Y, Ozawa T, et al. Multilocular giant epidermal cyst. Br J Dermatol. 2004;151:943-5.

10. DebaizeS, Gebhart M, Fourrez T et al. Squamous cell carcinoma arising in Giant epidermal cyst. Acta Chir Belg.2002 jun;102(3):196-8.

11. Wani I, Bhat B, Mir I et al. Giant Sebaceous cyst of scalp: A case report. The Internet journal of dermatology. 2008;6:2.

12. Chiu MY, Ho ST. Squamous cell carcinoma arising from an epidermal cyst. Hong Kong Med J. 2007;13:482-4.

13. Pergola GD, Silvestris F. Obesity as a major risk factor for cancer. Journal of Obesity. 2013;2013:291546. doi:10.1155/2013/291546.

14. Humphries MP, Jordan VC, Speirs V. Obesity and male breast cancer: provocative parallels. BMC Medicine. 2015;13:134. doi:10.1186/s12916-015-0380-x

15. Niewoehner CB, Schorer AE. Gynaecomastia and breast cancer in men. BMJ. 2008; 336:709.

16. Cook MB, Guenel P, Brinton LA. Tobacco and alcohol in relation to male breast cancer: An analysis of the male breast cancer pooling project consortium. Cancer Epidemiol Biomarkers Prev. 2015Mar: 24(3):520-531.
17. Goyal S,Goyal S,Garg GK. Male breast carcinoma:Case report with retrospective study of breast carcinoma. Arch Med Health Sci 2014;2:202-5.

18. Farrokh F, Ansaripour E, Fallah Rastegar Y. Simultaneous bilateral male breast cancer:A case report and review of the literature. Iran J Cancer Prev 2010;3:199-203.

19. Zygogianni AG, Kyrgias G, Gennatas C, IIknur A, Armonis $\mathrm{V}$, Tolia $\mathrm{M}$ et al. Male breast carcinoma: Epidemiology, risk factors and current therapeutic approaches. Asian Pac J Cancer Prev 2012;13:15-9.

20. World Health Organization Classification of Tumours. Lyon :IARC Press;2003. Pathology and Genetics. Tumour of the Breast and female genital organs.

21. Afroz N, Zaheer S,Khan N, Khan MA. Primary of breast:a case report and review of literature. Iranian Journal of Pathology.2010;5:204-7.

22. Biswas S, Chakraboty J,Biswas RKR, Rahman QM, Sanyal $\mathrm{S}, \mathrm{Pal} \mathrm{G}$ et al. Primary breast sarcoma-Report of two cases. Indian J Path micro.2002;45(1):93-7.

23. Deodhar SD,Khope SS, Kinare SG. Fibrosarcoma of the breast(a case report).J Postgrad Med.1983;29(2):123-4.

24. Callery CD, Rosen PP. Kinne DW.Sarcoma of breast. A study of 32 patients with reappraisal of classification and therapy. Ann surg. 19wu 85;201(4):527-32.

25. Kidmas AT, Ugwu BT, Manasseh AN, Iya D, Opaluwa AS. Male breast malignancy in Jos University Teaching Hospital. West Afr J Med.2005;24(1):36-40.

*Corresponding author:

Dr. Mahasweta Mallik, C-9, SECL Colony, Bhatgaon, Surajpur, Chattisgarh, India

Phone: +91 9386882796

Email: mahasweta3112@yahoo.com

Financial or other Competing Interests: None. 